\title{
New Expressions
}

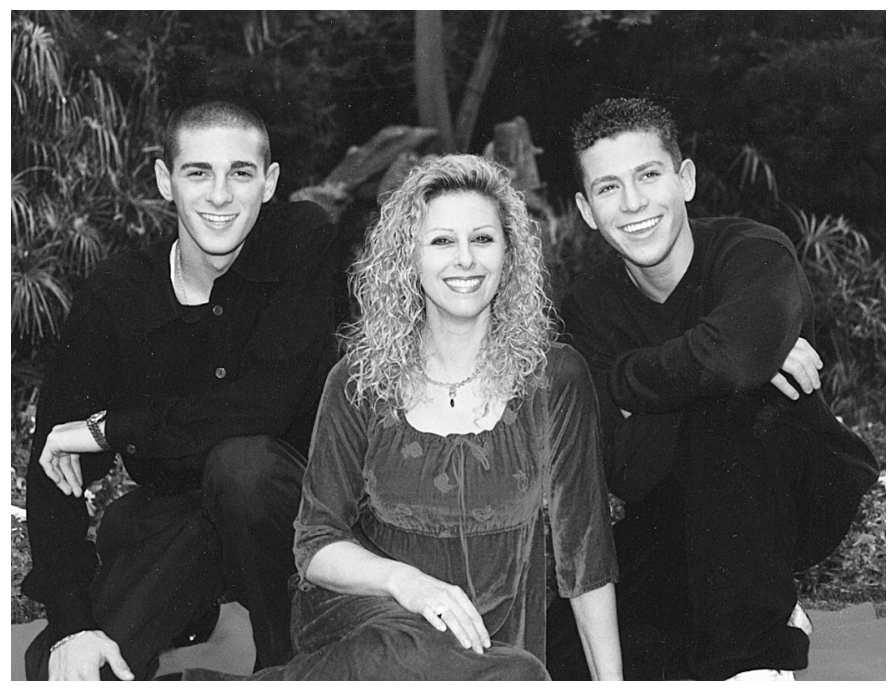

Photo by Laura Gornbein.

\section{Moments Fleeting}

A Lamaze Certified Childbirth Educator and mother of two, Amy Austin says, "It seems like a 'blink' when I remember my own Lamaze class and reunion." Amy wrote the following poem for her two sons, now ages 16 and 19. While trying to come up with a title for her verse, she decided on "Moments Fleeting," because these words "express my feelings that it seems like a blink since the boys were born."

Enraptured by you

Captured

Moments fleeting

My heart is beating

Each time you enter the room

Do you catch me staring?

Amazed by what G-d created within

So long ago but yet like yesterday

Sometimes my insides yearn for that kick

That hiccup

The moment of life-giving high

Separate now but still bonded together

Look, look everyone, look what I have done

You all but encompass me

You are now on your way to yourself

Go and follow your path

G-d is with you forevermore

I am never far behind. . .

-Amy Austin, RN, BS, LCCE 